\title{
LIPOSSOMAS DE LONGA-CIRCULAÇÃO COMO ESTRATÉGIA PROMISSORA PARA O TRANSPORTE E BIODISPONIBILIZAÇÃO DE FÁRMACOS NO TRATAMENTO DO CÂNCER
}

\author{
LONG-CIRCULATING LIPOSOMES AS A PROMISING STRATEGY FOR THE \\ TRANSPORT AND BIOAVAILABILITY OF DRUGS IN CANCER TREATMENT
}

Camila Fabiano de Freitas $^{1^{*}}$, Vagner Roberto Batistela ${ }^{2}$, Wilker Caetano ${ }^{1}$, Noboru Hioka ${ }^{1}$

${ }^{1}$ Departamento de Química, Universidade Estadual de Maringá (Maringá/PR, Brasil).
2 Departamento de Tecnologia, Universidade Estadual de Maringá. (Umuarama/PR,
Brasil).
* Avenida Colombo, 5790 - Bloco 16, Sala 05, CEP 87020-900, Maringá/PR, Brasil. E-mail:
cffmarin2@uem.br

Submetido em: 17/12/2019; Aceito em: 18/03/2020.

\section{RESUMO}

Nos últimos anos a nanotecnologia revelou-se uma forte aliada no desenvolvimento da Química Medicinal. Nessa vertente, destacam-se os lipossomas que além de serem modelos de membrana celular também são excelentes sistemas biocompatíveis de formulação, carreamento e liberação de fármacos. Entretanto, os lipossomas apresentam limitações relacionadas à sua baixa estabilidade em solução e rápida eliminação da circulação sanguínea. Esses fatores acabam impedindo o acúmulo dessas estruturas em tecidos tumorais, inclusive pelo efeito de permeabilidade e retenção (efeito EPR). Diante deste quadro, diversas estratégias vêm sendo desenvolvidas com o objetivo de aumentar a estabilidade e principalmente o tempo de circulação sanguínea dos lipossomas. Pesquisas recentes têm mostrado a obtenção de lipossomas modicados superficialmente com polietilenoglicol (PEG), com copolímeros tribloco do tipo ABA ou ainda com ligantes sítios específicos. Nesse sentido, o presente artigo traz uma revisão sobre as principais contribuições científicas no desenvolvimento, otimização e aprimoramento de lipossomas como sistemas de longa circulação visando novas estratégias de formulação de medicamentos para o tratamento do câncer.

Palavras-chave: Copolímeros Tribloco. Formulação de medicamentos. Lipossomas. Lipossomas de Longa-circulação. Tratamento do câncer.

\section{ABSTRACT}

In recent years, nanotechnology has been a strong ally to Medicinal Chemistry. Liposomes stand out, being cell membrane models and excellent biocompatible drug delivery systems. However, liposomes have limitations due to their low stability in solutions and rapid elimination from the blood stream. These factors prevent the accumulation of these structures in tumor tissues, as well as the effects of permeability and retention (EPR effect). Given this scenario, several 
strategies have been developed aiming to increase the stability and the circulation of liposome in the blood stream. Recent research has shown that surface-modified liposomes with polyethylene glycol (PEG), triblock ABA-like copolymers or site-specific ligands are able to overcome these issues. With that in mind, this article brings a review of the main scientific contributions in the development, optimization and improvement of liposomes as long circulation systems aiming at new strategies for drug formulation in cancer treatment.

Keywords: Cancer Treatment. Drug Formulation. Liposomes. Long Circulating Liposomes. Triblock Copolymers.

\section{INTRODUÇÃO}

Nos últimos 40 anos, a comunidade científica avançou progressivamente no desenvolvimento da Química Medicinal (DO AMARAL et al., 2017). A vertente multidisciplinar desta área possibilitou a obtenção de sistemas capazes de encapsular, transportar e entregar fármacos em regiões específicas no organismo. Mais especificamente, o conhecimento acerca da nanotecnologia vem permitindo o desenvolvimento de medicamentos e terapias mais eficazes (KESKINBORA; JAMEEL, 2018). Esta estratégia visa melhorar a administração de medicamentos no tecido doente, minimizando os efeitos colaterais causados pelos medicamentos convencionais (GWINN; VALLYATHAN, 2006). Nesse sentido, as nanopartículas são capazes de proteger os fármacos in vivo, além de aumentarem sua difusão e absorção epitelial, modificando a sua farmacocinética e perfil de distribuição (COUVREUR, 2013; AULA et al., 2015).

Neste contexto, lipossomas são sistemas nanoestruturados para a solubilização e transporte de fármacos em meio aquoso (AKBARZADEH et al., 2013; BULBAKE et al., 2017; BELTRÁN-GRACIA et al., 2019). De modo geral, são estruturas coloidais, com diâmetros entre $20 \mathrm{~nm}$ e $5 \mu \mathrm{m}$, formados a partir da organização de fosfolipídios na forma de bicamadas lipídicas. Os formatos mais comuns são unilamelar (bicamada única), multilamelar (bicamadas concêntricas) ou multivesicular (vesículas pequenas inseridas em uma vesícula maior) (BATISTA et al., 2007; FANCIULLINO; CICCOLINI, 2009). A bicamada lipídica armazena em seu interior um poço aquoso, no qual podem ser incorporados fármacos de caráter hidrofílico. Por outro lado, fármacos hidrofóbicos ou anfifílicos localizam-se preferencialmente na bicamada lipídica.

A estrutura química de fosfolipídios é constituída por duas cadeias de ácidos graxos (saturadas e/ou insaturadas), um grupo fosfato, um grupo glicerol e grupo funcional com uma cabeça polar. Esta parte polar confere versatilidade aos fosfolipídios dada a possibilidades de serem grupos aniônicos, catiônicos ou zwiteriônicos. Dentre as classes de fosfolipídios, destacam-se as fosfatidilserinas (PS), as fosfatidiletanolaminas (PE), as fosfatidilcolinas (PC) e os fosfatidilgliceróis (PG). Além disso, os fosfolipídios podem ser tanto de origem natural quanto sintética.

Uma vez que os fosfolipídios são constituintes naturais das membranas celulares, os lipossomas são nanoestruturas biocompatíveis e por isso empregados como sistema de incorporação, biotransporte e biodisponibilização de fármacos (TORCHILIN, 2005; AKBARZADEH et al., 2013; XING; HWANG; 
LU, 2016). Uma vantagem intrínseca dos lipossomas é a capacidade de interação com a membrana biológica, sendo uma estratégia na entrega de fármacos. Dentre os mecanismos de interação destacam-se a endocitose, a fusão e a troca lipídica (MOGHIMIPOUR; HANDALI, 2013).

Por outro lado, lipossomas convencionais, ou seja, constituídos apenas por fosfolipídios, possuem limitações relacionadas à sua baixa estabilidade termodinâmica e cinética em solução. Isso se deve aos processos de agregação e fusão entre as vesículas originados pela elevada área superficial e pelo caráter hidrofóbico (FREITAS et al., 2019a). A baixa estabilidade em solução pode ser contornada armazenando-os no estado sólido (MUFAMADI et al., 2011), sendo a liofilização a principal via de armazenamento lipossomal. Dentre as características, a matriz sólida obtida deve ser fácil e rapidamente reidratada com solução compatível, permitindo que as vesículas retornem ao seu estado inicial sem perdas do fármaco incorporado (CROWE; REID; CROWE, 1996 CHEN et al., 2010). Muitas vezes a obtenção deste sólido envolve a adição de agentes crioprotetores e lioprotetores (CHEN et al., 2010), conservando a estrutura das vesículas durante o processo de congelamento e minimizando processos de hidrólise e oxidação dos fosfolipídios, aumentando o tempo de prateleira dos formulados (FRÉZARD; MG; ROCHA, 2005; BATISTA et al., 2007; AKBARZADEH et al., 2013; BULBAKE et al., 2017).

Um outro problema é relacionado ao pequeno tempo de circulação sanguínea. Isso ocorre porque a superfície lipossomal liga-se rapidamente às opsoninas do plasma sanguíneo, fazendo com que os macrófagos os reconheçam como corpos estranhos ao organismo, capturando-os da circulação (ROOIJEN; SANDERS, 1996; MEHVAR, 2018). Nessas circunstâncias, a propensão do Sistema Reticular Endotelial (SRE) para remover lipossomas da circulação sanguínea é um fator altamente limitante no direcionamento dos lipossomas para outros tecidos além do fígado, baço e pulmão (BUGELSKI et al., 1982). Por essa razão, a quantidade de fármaco capaz de alcançar o tecido alvo é bastante reduzida, implicando em doses elevadas e resultando em graves efeitos colaterais (AKBARZADEH et al., 2013; SERCOMBE et al., 2015; DAVE et al., 2019).

Como alternativa, a fluidez da bicamada lipídica, o diâmetro hidrodinâmico, a lamelaridade e o caráter superficial dos lipossomas podem ser modificados para driblar a baixa estabilidade e o curto intervalo de circulação sanguínea (MOGHIMI; SZEBENI, 2003; IMMORDINO; CATTEL, 2006a; MINEART et al., 2018). Além disso, a utilização de ligantes sítio-específicos tem representado uma estratégia importante do direcionamento seletivo de lipossomas ao tecido tumoral (KHAN et al., 2020). Isto pode ser feito tanto pela modificação química dos fosfolipídios a partir de processos sintéticos como pela adição de agentes estabilizadores das vesículas, mantidos por interações físicas (AKBARZADEH et al., 2013; SERCOMBE et al., 2015; DAVE et al., 2019). Neste trabalho de revisão, serão apresentadas algumas possibilidades de modificações em lipossomas visando a obtenção de formulados estáveis para aplicações em Química Medicinal, principalmente para o tratamento do câncer. 


\section{METODOLOGIA}

A elaboração da presente revisão bibliográfica foi conduzida por meio de uma pesquisa exploratória e de modo qualitativo, a partir de artigos científicos publicados em revistas com elevados fatores de impacto relacionados ao tema proposto. O levantamento bibliográfico foi realizado em sites de pesquisa acadêmica especializada: Science Direct, Web of Science, Google Acadêmico e Portal de Periódicos da CAPES.

Como termos de busca foram utilizados: vesículas lipídicas (lipid vesicles), lipossomas de longa-circulação (long-circulating liposomes), lipossomas revestidos (coated liposomes), lipossomas furtivos (stealth liposomes), lipossomas peguilados (pegylated liposomes), lipossomas sítio-específicos (sitespecific liposomes), lipossomas estericamente estabilizados (sterically stabilized liposomes), lipossomas modificados (modified liposomes), lipossomas mistos (mixed liposomes), lipossomas híbridos (hybrid liposomes), nanopartículas híbridas de polímeros-lipídios (polymer-lipid hybrid nanoparticles) e funcionalização de lipossomas (liposome functionalization).

A coleta de dados seguiu a leitura inicial exploratória de todo o material selecionado, verificando-se a relevância para este trabalho. Em seguida, após a seleção dos textos, realizou-se a análise e interpretação das informações por meio de leitura analítica com a finalidade de ordenar e sumarizar as informações contidas nas fontes. Devido à especificidade do tema avaliado, não houve delimitação do período de publicação para as referências pesquisadas.

\section{DESENVOLVIMENTO}

\section{ESTRATÉGIAS PARA A MODIFICAÇÃO DE LIPOSSOMAS}

\section{Modificações Lipossomais: Panorama Geral}

As modificações lipossomais tem por objetivo a melhoria de suas propriedades em relação à incorporação, ao carreamento e à entrega de fármacos. Essas modificações podem ser realizadas mediante o aprimoramento dos lipossomas convencionais, relacionadas à sua composição lipídica e/ou em sua carga superficial a partir da adição sinais moleculares, conforme representado na Figura 1 (SERCOMBE et al., 2015; KHAN et al., 2020). São várias as possibilidades de modificação, uma vez que lipossomas convencionais podem ser catiônicos, aniônicos ou zwiteriônicos, dependendo do grupo polar presente em sua estrutura (ALLEN, 2015; DAVE et al., 2019).

$\mathrm{Na}$ Figura 1 encontra-se uma representação das principais modificações que podem ser realizadas na estrutura lipossomal. Nesta, evidencia-se que os fármacos hidrofílicos tendem a se concentrar no poço aquoso interno enquanto os fármacos hidrofóbicos alocam-se preferencialmente na bicamada lipídica. Dentre as estratégias de modificação citadas na Figura 1, a adição de agentes furtivos à superfície lipossomal se destaca. Essas espécies permitem que os lipossomas permaneçam por tempo suficiente na corrente sanguínea sem serem reconhecidos e capturados pelas células do SRE (MOGHIMI; SZEBENI, 2003; KHAN et al., 2020). 
Para a obtenção de lipossomas de longa circulação, as modificações podem ser realizadas a partir da formação de ligações covalentes entre os fosfolipídios e as extremidades das cadeias poliméricas. Dentre os principais polímeros utilizados destacam-se o polietilenoglicol (PEG), o poli(ácido lático-co-ácido glicólico) (PLGA), o poliácido láctico (PLA), a policaprolactona (PCL), a polivinilpirrolidona (PVP) e uma ampla gama de copolímeros (LE MEINS et al., 2013; DAVE et al., 2019). De modo semelhante, as cadeias poliméricas e fosfolipídicas também podem ser combinadas por meio de interações intermoleculares, evitando-se a rota sintética. Essas alterações são de execução experimental relativamente simples e envolvem a adição de pequenas quantidades de outros constituintes, como é o caso do colesterol, capaz de modular a fluidez da bicamada lipídica (BRIUGLIA et al., 2015). Algumas alternativas bastante promissoras envolvem o uso de polietilenoglicol (PEG) e copolímeros tribloco, detalhados adiante.

Figura 1 - Características estruturais dos alguns tipos de lipossomas: convencionais, longa-circulação (peguilados), longa-circulação (copolímeros tribloco) e sítio-específicos (com moléculas quimicamente ligadas visando aumenta o reconhecimento celular).

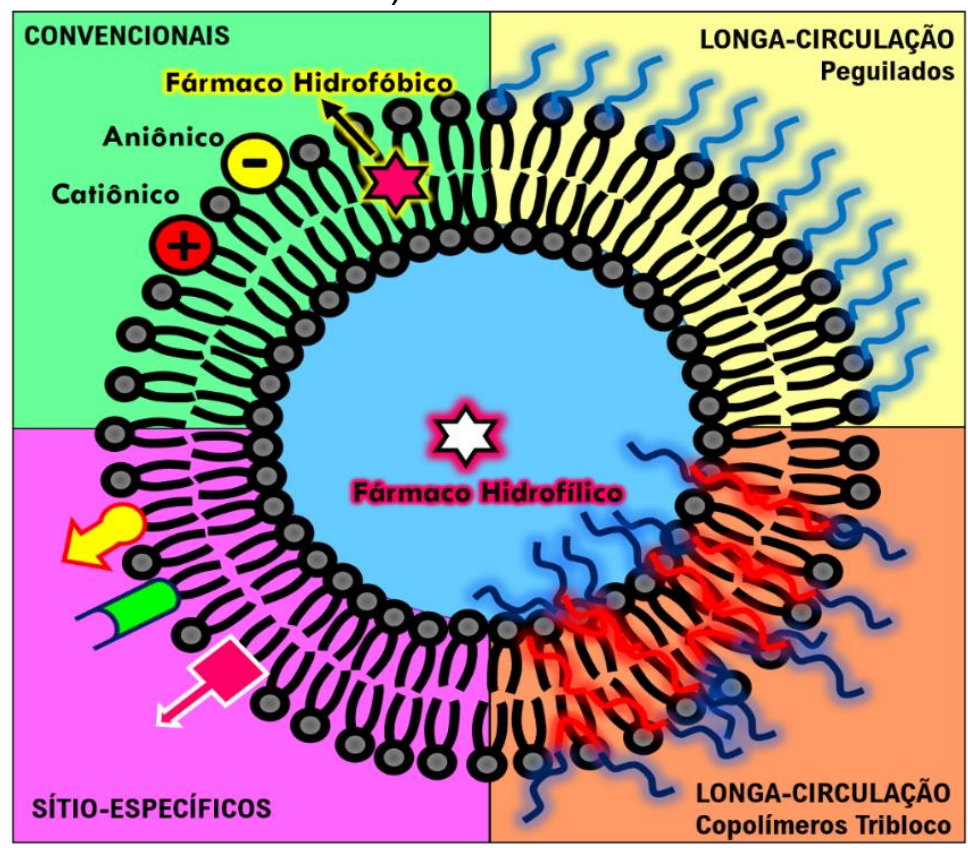

Fonte: os autores.

Em outra abordagem, moléculas bioativas também podem ser covalentemente ligadas à superfície lipossomal, permitindo a obtenção de lipossomas sítio-específicos (AKBARZADEH et al., 2013; PANDYA et al., 2019). Essas nanoestruturas são aplicadas no direcionamento seletivo dos princípios ativos à região de ação desejada (alvo celular), conforme Figura 1 (SERCOMBE et al., 2015; DE FREITAS et al., 2019). Além disso, vesículas modificadas com moléculas fluorescentes constituem uma interessante abordagem na visualização e no diagnóstico de tecidos lesionados, mediante acúmulo no tecido doente e irradiação com fonte luminosa adequada (SELECl et al., 2017). Vale destacar que, a adição de ligantes sítio-específicos e fluorescentes estão 
relacionados ao direcionamento seletivo e ao diagnóstico, não sendo atribuído a eles a característica de estabilização cinética.

\section{Desenvolvimento de Lipossomas de Longa-circulação}

As primeiras etapas no desenvolvimento de lipossomas capazes de circular por tempo prolongado na corrente sanguínea foram desenvolvidas no final da década de 80 (ALLEN; HANSEN; RUTLEDGE, 1989; LASIC; DAVID NEEDHAM, 1995; NAGAYASU; UCHIYAMA; KIWADA, 1999). Os estudos levaram à conclusão de que apenas os lipossomas com diâmetros hidrodinâmicos próximos a $100 \mathrm{~nm}$ mantinham-se por tempo suficiente na corrente sanguínea. Por outro lado, lipossomas com diâmetros superiores a 200 $\mathrm{nm}$ eram mais rapidamente reconhecidos e eliminados pelos macrófagos (TORCHILIN et al., 1994; LASIC; DAVID NEEDHAM, 1995).

$\mathrm{Na}$ mesma época, foram avaliados diferentes tipos de fosfolipídios a fim de verificar como a estrutura química poderia influenciar em seu tempo de circulação sanguínea. Esses estudos levaram à conclusão de que a utilização de fosfolipídios saturados favorecia a permanência dos lipossomas em circulação para aplicações endovenosas (ALLEN; HANSEN; RUTLEDGE, 1989), pois apresentam temperaturas de transição de fase $\left(T_{m}\right)$ superiores à temperatura corpórea $\left(37^{\circ} \mathrm{C}\right)$. Como exemplo, pode-se citar o 1,2-dipalmitoil-snglicero-3-fosfatidilcolina (DPPC), cuja transição ocorre em $41,4^{\circ} \mathrm{C}$ (MABREY; STURTEVANT, 1976). Ressalta-se que a $\mathrm{T}_{\mathrm{m}}$ se refere a uma temperatura ou faixa de temperaturas (sistemas mistos) em que ocorre a transição entre a fase gel ou "rígida" para a fase cristal-líquido ou fluida. Sendo assim, em temperaturas inferiores à $T_{m}$, os fosfolipídios têm movimento restrito e bem ordenado (MABREY; STURTEVANT, 1976). Dessa forma, minimiza-se a perda por vazamento dos fármacos antes de atingir a região de interesse. Fosfolipídios insaturados, por outro lado, além de perderem parte da carga de fármaco devido às baixas $T \mathrm{~m}$, também apresentam indesejáveis reações de hidrólise e oxidação (FRUHWIRTH; LOIDL; HERMETTER, 2007).

Apesar das informações iniciais acerca do diâmetro dos lipossomas e sobre o tipo de fosfolipídio, os tempos de circulação obtidos em ensaios in vitro e in vivo ainda não eram condizentes com o almejado para aplicações biológicas endovenosas (ALLEN; HANSEN; RUTLEDGE, 1989). Novas pesquisas passaram a investigar a modificação superficial dos lipossomas, a partir de materiais hidrofílicos capazes de "driblar" os macrófagos do SRE (WOODLE, 1995). Diante disso, foi realizada a modificação superficial dos lipossomas com gangliosídeos, especificamente o monosialoganglíosideo (GM1) (GABIZON; PAPAHADJOPOULOS, 1988). Uma vez que os gangliosídeos são glicoesfincolipídeos que se localizam na região externa de membranas plasmáticas, concentrando-se principalmente no sistema nervoso, não são estruturas reconhecidos pelo SRE (HAKOMORI, 1981). Assim, poderiam ser incorporadas à estrutura de vesículas lipossomais, com o intuito de evitar o efeito do SRE. Considera-se que esses estudos levaram ao desenvolvimento do termo "estabilização estérica", com o intuito de mimetizar a membrana dos eritrócitos (PINNADUWAGE; HUANG, 1988). Essas estruturas são abundantes no sangue humano na ordem entre 4,5 e $6,0 \times 10^{6} \mathrm{~mm}^{-3}$ e são responsáveis pelo 
transporte de oxigênio e dióxido de carbono pelo corpo (HELMS; GLADWIN; KIM-SHAPIRO, 2018).

A estratégia empregada baseava-se no fato de que a inclusão dos gangliosídeos conferiria carga negativa à superfície lipossomal. Dessa forma, o caráter hidrofílico atrelado à carga melhoraria a estabilidade do lipossoma no plasma, prolongando o seu tempo de meia-vida no sangue, reduzindo a captação pelo fígado e baço (MOGHIMI; SZEBENI, 2003; KHAN et al., 2020). Contudo, uma série de problemas foram relatados, acarretando na dificuldade de aceitação e utilização dos lipossomas revestidos com a GM1 pela comunidade científica (LASIC; DAVID NEEDHAM, 1995). A partir de então, novas estratégias passaram a ser pensadas e desenvolvidas, almejando-se um revestimento mais seguro, barato, reprodutível e com maior confiabilidade clínica.

\section{Lipossomas Peguilados}

A estratégia seguinte foi revestir os lipossomas com polietilenoglicol (PEG), um polímero biocompatível e biodegradável amplamente utilizado em formulações de fármacos (D'SOUZA; SHEGOKAR, 2016), em um processo conhecido como "peguilação", conforme Figura 2 (IMMORDINO; CATTEL, 2006b). De modo geral, a técnica de peguilação é uma das mais bem-sucedidas para melhorar a distribuição de proteínas, oligonucleotídeos e princípios ativos (TURECEK et al., 2016).

Figura 2 - Estrutura do fosfolipídio fosfatidiletanolamina peguilada (DSPE-PEG) em que "R" são as cadeias alquilicas e a representação dos Lipossomas Peguilados.

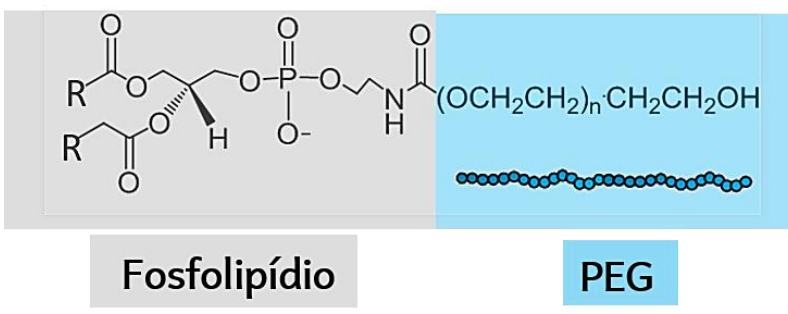

Fonte: os autores.

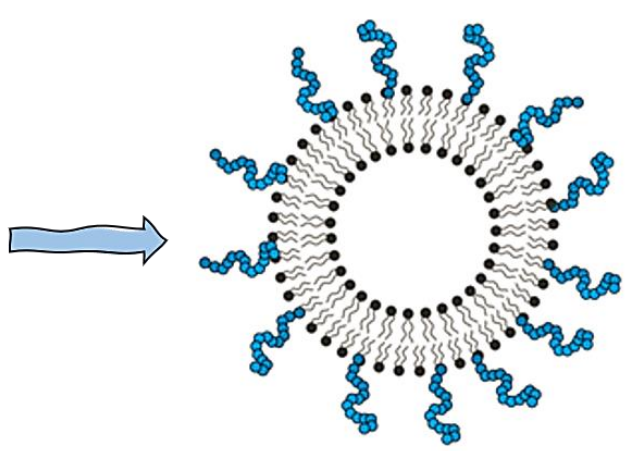

Lipossomas Peguilados

A modificação superficial dos lipossomas com PEG realizada pela combinação física das cadeias fosfolipídicas e poliméricas pode ser alcançada por duas metodologias principais: a de adsorção e a de incorporação. A primeira e mais simples está relacionada à adsorção das cadeias poliméricas em lipossomas pré-formados (IMMORDINO; CATTEL, 2006b). Neste caso, há o preparo das vesículas lipossomais pelas metodologias convencionais tais como dispersão sólida, injeção etanólica e evaporação em fase reversa (HUANG; DAI, 2013). Em seguida, a solução polimérica é adicionada à dispersão lipossomal, de modo que as interações intermoleculares direcionem o revestimento. $\mathrm{Na}$ segunda metodologia, as cadeias poliméricas e fosfolipídicas são adicionadas 
em conjunto desde o início. Assim, o polímero participa da etapa de formação dos lipossomas. A metodologia de preparo segue a técnica de dispersão sólida (IMMORDINO; CATTEL, 2006b; MILLA; DOSIO; CATTEL, 2011; HUANG; DAI, 2013; FREITAS et al., 2019a). Uma terceira estratégia envolve a ligação covalente do polímero ao fosfolipídio. Amostras comercializadas constituídas pelo fosfolipídio covalentemente ligado ao PEG, como é o caso do fosfatidiletanolamina (DSPE-PEG), vem sendo amplamente utilizadas, Figura 2 (BULBAKE et al., 2017).

A peguilação acarreta em melhorias na farmacocinética e na farmacodinâmica, aumentando a solubilidade em água, protegendo os fármacos contra a ação enzimática e degradação (TURECEK et al., 2016). Além disso, é possível reduzir a depuração renal e limitar a ocorrência de reações imunogênicas e antigênicas (TORCHILIN, 2005; SILVA et al., 2016). Assim, a utilização do PEG melhora não apenas a estabilidade e o tempo de circulação, mas também a capacidade de direcionamento "passivo" dos fármacos. Essa característica é atribuída ao Efeito de Permeabilidade e Retenção (Efeito EPR) devido à má formação vascular dos tecidos tumorais, favorecendo o acúmulo preferencial das nanopartículas em suas fenestrações, melhorando os efeitos terapêuticos e redução da toxicidade dos princípios ativos encapsulados (FANG; NAKAMURA; MAEDA, 2011). Além disso, o revestimento superficial hidrofílico é capaz de prevenir o reconhecimento e consequente associação com as opsoninas no plasma, inibindo o processo de captura pelo SRE (TORCHILIN et al., 1994).

Os resultados clínicos iniciais empregando-se lipossomas peguilados foram promissores e suportados pela ausência de toxicidade, não imunogenicidade e aprovação do PEG pela FDA (do inglês: "Food and Drug Administration") para aplicações parenterais em seres humanos (HUYNH; LAUTRAM, 2010). Além disso, os estudos clínicos demonstraram que lipossomas peguilados seriam capazes de permanecer na circulação sanguínea com um tempo de meia-vida de aproximadamente 45 horas, suficiente para que os fármacos incorporados pudessem atingir o tecido alvo (SINGH; JR, 2009). No entanto, estudos posteriores mostraram que após atingir a região tumoral, os lipossomas peguilados apresentavam dificuldades na internalização dos princípios ativos encapsulados (OGRIS et al., 1999).

Os ensaios clínicos reconheceram uma outra complicação relacionada à perda dos efeitos furtivos após a aplicação da segunda dose da formulação (ISHIDA et al., 2005) conhecido como Depuração Sanguínea Acelerada ou fenômeno ABC (do inglês: Accelerated Blood Clearance) (DAMS et al., 2000). Dessa forma, a partir da segunda dose, os lipossomas eram rapidamente reconhecidos e captados pelos macrófagos, acumulando-se extensivamente no fígado (DAMS et al., 2000). Inicialmente, foi demonstrado que o efeito ABC tratava-se de uma resposta à primeira aplicação endovenosa, relacionado à dosagem lipídica empregada (LAVERMAN et al., 2001). Posteriormente, foi constatado que lipossomas preparados a partir de fosfolipídios insaturados intensificavam este efeito (XU et al., 2014).

O fenômeno $A B C$ pode reduzir a eficácia terapêutica dos fármacos encapsulados, alterando a distribuição tecidual padrão dos medicamentos, além de causar outros efeitos colaterais. Por esses motivos, soluções para esse 
entrave passaram a ser um importante alvo da comunidade científica. Nesse contexto, novas abordagens acerca do desenvolvimento de lipossomas de longa circulação capazes de evadir à opsonização passaram a ser consideradas.

Vale destacar que até o presente momento existem várias formulações envolvendo lipossomas aprovadas pelo FDA (BULBAKE et al., 2017). Apesar das dificuldades encontradas, as formulações comerciais envolvem lipossomas convencionais, misturas de diferentes fosfolipídios e em alguns sistemas contêm colesterol como aditivo. Dentre as formulações aprovadas, duas envolvem a peguilação. O primeiro fármaco aprovado foi o Doxilß em 1995 para o tratamento do câncer de ovário e de mama (A'HERN; GORE, 1995). Em 2015 o Onivyde® foi aprovado para o tratamento de câncer pancreático em estágio metastático (TRAN et al., 2017).

\section{Lipossomas Associados a copolímeros tribloco}

Os copolímeros tribloco são disponíveis comercialmente para uso humano como Pluronic® (ou "Poloxâmeros"). Tratam-se de materiais biocompatíveis e estruturalmente constituídos por dois grupos hidrofílicos de poli(óxido de etileno) (PEO) e um grupo hidrofóbico de poli(óxido de propileno) (PPO), ligados em uma sequência $(E O)_{a}(P O) b(E O) a$, conforme Figura $3 A$ (ALEXANDRIDIS; HOLZWARTHF; HATTON, 1994; ALEXANDRIDIS; HATTON, 1995). Essa classe de copolímeros em bloco é composta por mais de cinquenta diferentes macromoléculas, podendo existir na forma líquida, pastosa ou em flocos. A proporção de grupos EO e grupos $P O$ no copolímero tribloco pode variar de 10 a 140 cadeias repetitivas para cada grupo EO e/ou PO (ALEXANDRIDIS; HATTON, 1995; BODRATTI; ALEXANDRIDIS, 2018).

Em solução aquosa, os copolímeros tribloco se auto-agregam na forma de micelas copoliméricas nanoestruturadas do tipo core-shell em condições superiores à sua concentração micelar crítica (CMC) e temperatura micelar crítica (TMC). Neste caso, o bloco PPO, mais hidrofóbico, forma o core interno da micela que é cercado pela corona hidrofílica constituída pelos blocos PEO, conforme representado na Figura 3B. O tamanho das estruturas micelares poliméricas depende essencialmente da extensão das cadeias de PEO e PPO.

$\mathrm{Em}$ concentrações inferiores à $\mathrm{CMC}$, em uma dada temperatura, os Poloxâmeros apresentam-se como monômeros independentes, sendo adicionados na preparação de lipossomas. O principal objetivo é o de evitar a perda do revestimento durante a circulação sanguínea e a consequente eliminação do efeito ABC (KOSTARELOS; TADROS; LUCKHAM, 1999). Nesse cenário, a utilização de Poloxâmeros abrangendo a bicamada lipídica consiste em uma alternativa potencial na obtenção da estabilização estérica. Isso se deve à maior interação das cadeias poliméricas com a bicamada lipídica, diferente do PEG que atua apenas no recobrimento superficial, como pode ser observado na Figura 3C. Assim a presença do bloco central hidrofóbico pode se orientar na bicamada fosfolipídica dependendo da metodologia de preparo.

Para a obtenção das vesículas mistas constituídas por fosfolipídio/copolímero são aplicadas as metodologias de adsorção e incorporação apresentados no item anterior para a peguilação. Na metodologia de adsorção, há o preparo das vesículas lipossomais pela técnica de dispersão sólida (HUANG; DAI, 2013) e, paralelamente, a solubilização do copolímero em meio aquoso. Assim como na 
peguilação por adsorção, a etapa seguinte envolve a combinação de ambas as soluções (lipossomal/copolimérica) para que o copolímero possa interagir com a bicamada, sendo adsorvido na superfície lipossomal previamente formada, conforme representado na Figura 4A. Por outro lado, na metodologia de incorporação polimérica ambos são misturados desde o início, possibilitando a obtenção de um filme fino misto. Dessa forma, a porção de polipropileno (PPO) da cadeia copolimérica passa a interagir fortemente com as cadeias hidrofóbicas dos fosfolipídios, conforme representado na Figura 4B (KOSTARELOS; TADROS; LUCKHAM, 1999).

Figura 3 - Representações dos copolímeros tribloco (Poloxâmeros) (A), Micelas copoliméricas (B) e Lipossomas estabilizados com copolímeros tribloco (C).

(A)

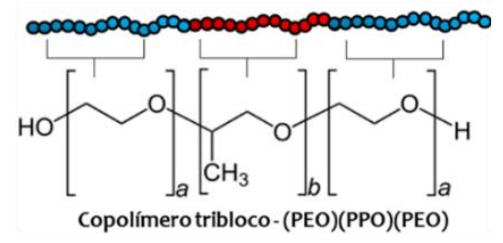

(B)

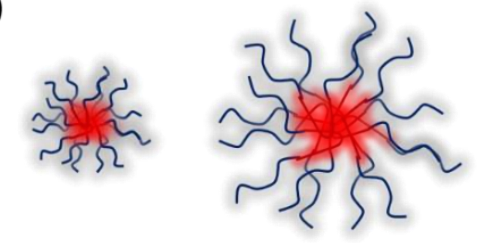

(C)

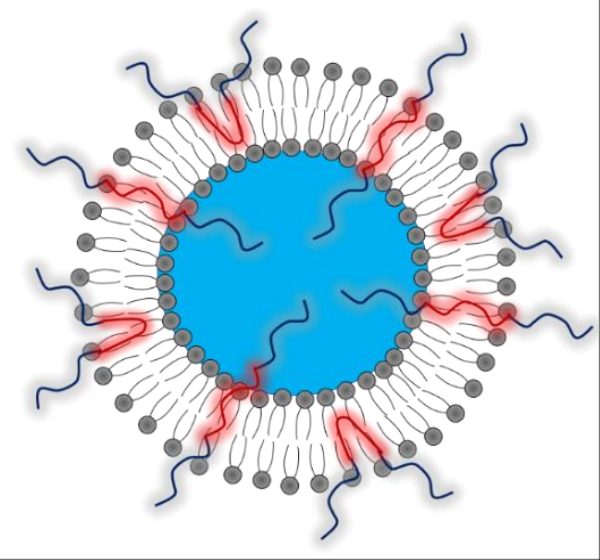

Fonte: os autores.

No preparo de lipossomas mistos, a concentração do copolímero deve ser mantida abaixo de sua concentração micelar crítica (CMC) (Figura 4C) (ALEXANDRIDIS; HOLZWARTHF; HATTON, 1994; ALEXANDRIDIS; HATTON, 1995; WU; LEE, 2009; FEITOSA; WINNIK, 2010). A utilização de concentrações superiores à CMC leva à formação de micelas compostas por fosfolipídios e copolímeros (Figura 4C) (SCHULZ; OLUBUMMO; BINDER, 2012). Não se desconsidera, inclusive, uma pequena formação de agregados do copolímero juntamente com os fosfolipídios, mesmo abaixo da sua concentração micelar crítica. De um modo geral, as concentrações utilizadas variam entre 1 e $20 \mathrm{~mol} \%$ (JOHNSSON et al., 1999; CHANDAROY et al., 2002; LIANG; MAO; NG, 2005; FREITAS et al., 2019a).

A combinação de pequenas quantidades do copolímero tribloco durante a formação do filme fino, empregando-se a metodologia de dispersão sólida tem se mostrado eficiente na obtenção de vesículas unilamelares pequenas e grandes (30 - 1000 nanômetros) (FREITAS et al., 2019a, 2019b). Trata-se na realidade de uma metodologia de formação ultrarrápida que combina, além do copolímero e fosfolipídio, uma condição de temperatura branda $\left(40-45^{\circ} \mathrm{C}\right)$ na presença de cavitação de baixa potência/frequência. O mecanismo de formação desses lipossomas foi reconhecido como sendo do tipo "Budding Off" (FREITAS et al., 2019b), caracterizado pela rápida formação de vesículas lipossomais maiores ("mães") a partir das quais se formam vesículas menores ("filhas") em tempos inferiores a quinze minutos (FREITAS et al., 2019b, 2019a). 
Nos últimos anos, vários estudos vêm sendo realizados com o objetivo de averiguar os efeitos ocasionados pela estabilização de Poloxâmeros nos lipossomas (LE MEINS et al., 2013; SANDEZ-MACHO et al., 2015; KLEMETSRUD et al., 2016; PIPPA et al., 2016), uma vez que as propriedades físicas e químicas dos Poloxâmeros podem ser moduladas mediante a modificação da razão molar entre os blocos PEO e PPO, a qual varia de 1:9 até 8:2 (ALEXANDRIDIS; HOLZWARTHF; HATTON, 1994). Assim, sua interação com estruturas celulares pode ser ajustada para a obtenção de biomateriais mais adequados. A localização dos copolímeros nos lipossomas costuma ser estudada por técnicas de microscopia de transmissão eletrônica (TEM), ressonância magnética nuclear (RMN), espalhamento de luz dinâmico (DLS), calorimetria diferencial de varredura (DSC) e espalhamento de raios-X a baixo ângulo (SAXS) (K.KOSTARELOS; P.F.LUCKHAM; TH.F.TADROS, 1995; JOHNSSON et al., 1999).

Figura 4 - Representação das metodologias de preparado de Lipossomas revestidos com copolímeros tribloco.

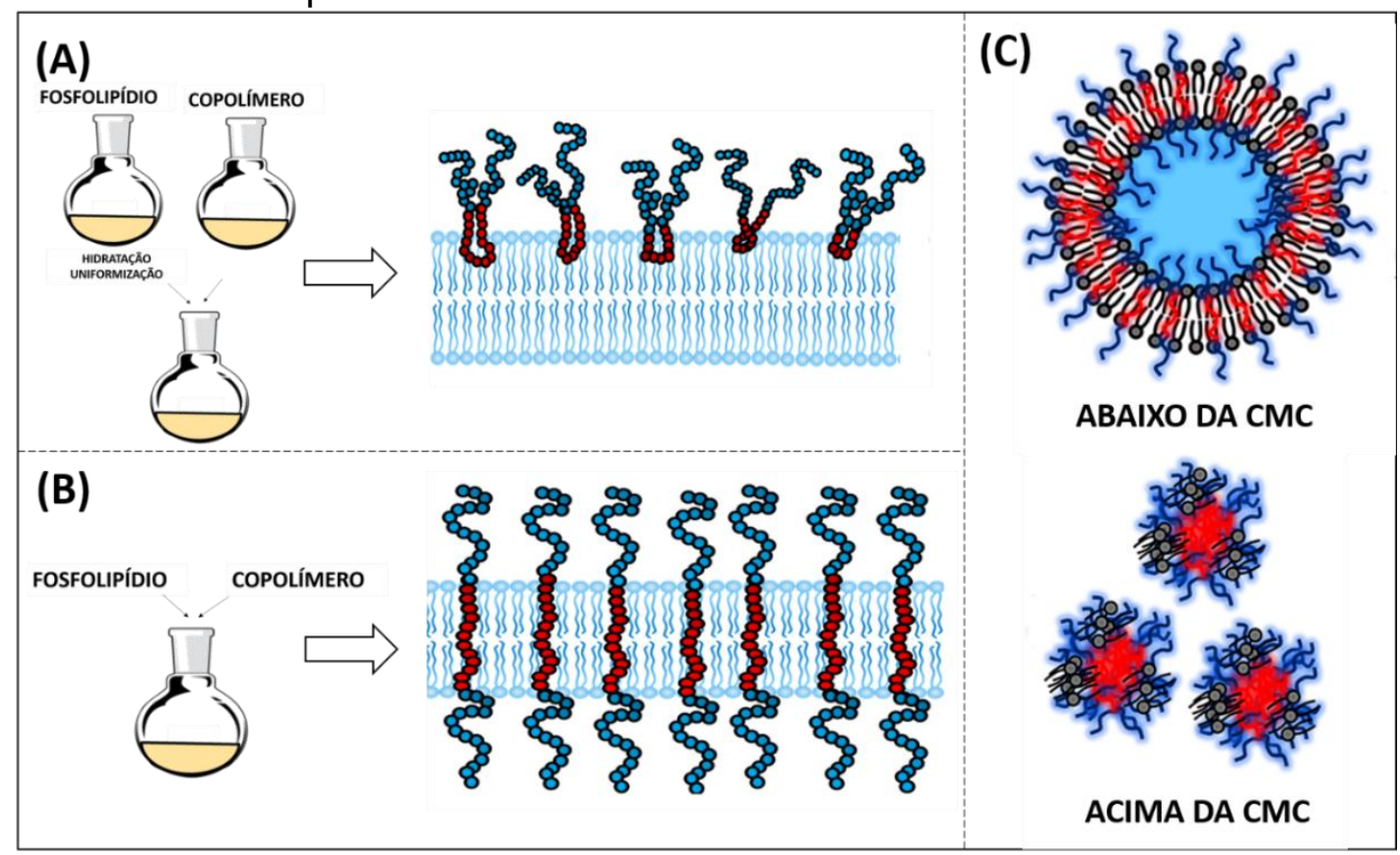

Notas: (A) Adsorção, (B) Incorporação. (C) Efeito da concentração de copolímero em sistemas mistos fosfolipídio/copolímero abaixo e acima da CMC.

Fonte: os autores.

Estudos mostraram que o preparo de lipossomas revestidos por método de adsorção promove significativo aumento no tamanho das vesículas lipossomais, dependente da razão PEO/PPO das cadeias copoliméricas (KOSTARELOS; TADROS; LUCKHAM, 1999). Por outro lado, lipossomas obtidos pelo método de incorporação copolimérica não sofreram aumento significativo no diâmetro hidrodinâmico (KOSTARELOS; TADROS; LUCKHAM, 1999). Nessas condições, o método de incorporação vem apresentando resultados mais efetivos na preparação de lipossomas de longa circulação, principalmente quando o copolímero utilizado apresenta longa cadeia hidrofílica 
(PEO). Além disso, a ineficiente adsorção de alguns Poloxâmeros em vesículas pré-formadas foi relatada (CHANDAROY et al., 2002).

Dentre os copolímeros tribloco empregados em conjunto com os fosfolipídios na preparação de lipossomas, destaca-se o Pluronic® F-127 (EO) ${ }_{106}(\mathrm{PO})_{70}(\mathrm{EO})_{106}$, também comercializado como Poloxâmero 407. O grande interesse neste polímero é devido às suas propriedades estarem de acordo com todos os requerimentos para aplicações biológicas e terapêuticas in vivo (ELKAMEL, 2002; AKASH M. S. H.; REHMAN K, 2015). Este copolímero melhora o transporte de fármacos através do endotélio cerebral, da barreira intestinal e provoca a transcrição da expressão de genes tanto in vitro como in vivo (AKASH M. S. H.; REHMAN K., 2015). Além disso, é capaz de interagir com a membrana celular diminuindo sua microviscosidade levando à formação de poros na membrana (AKASH M. S. H.; REHMAN K., 2015). Adicionalmente, também é capaz de acelerar o processo de "flip-flop", sendo essa uma de suas principais vantagens no revestimento de lipossomas (AKASH M. S. H.; REHMAN K., 2015).

\section{Lipossomas Sítio-Específicos}

Os sistemas sítio-específicos são aqueles que possuem ligantes de direcionamento incorporados à estrutura dos lipossomas. Na Figura $5 \mathrm{~A}$ encontra-se a representação de um sistema contendo ligantes de direcionamento em sua superfície.

Figura 5 - Representação dos lipossomas sítio-específicos

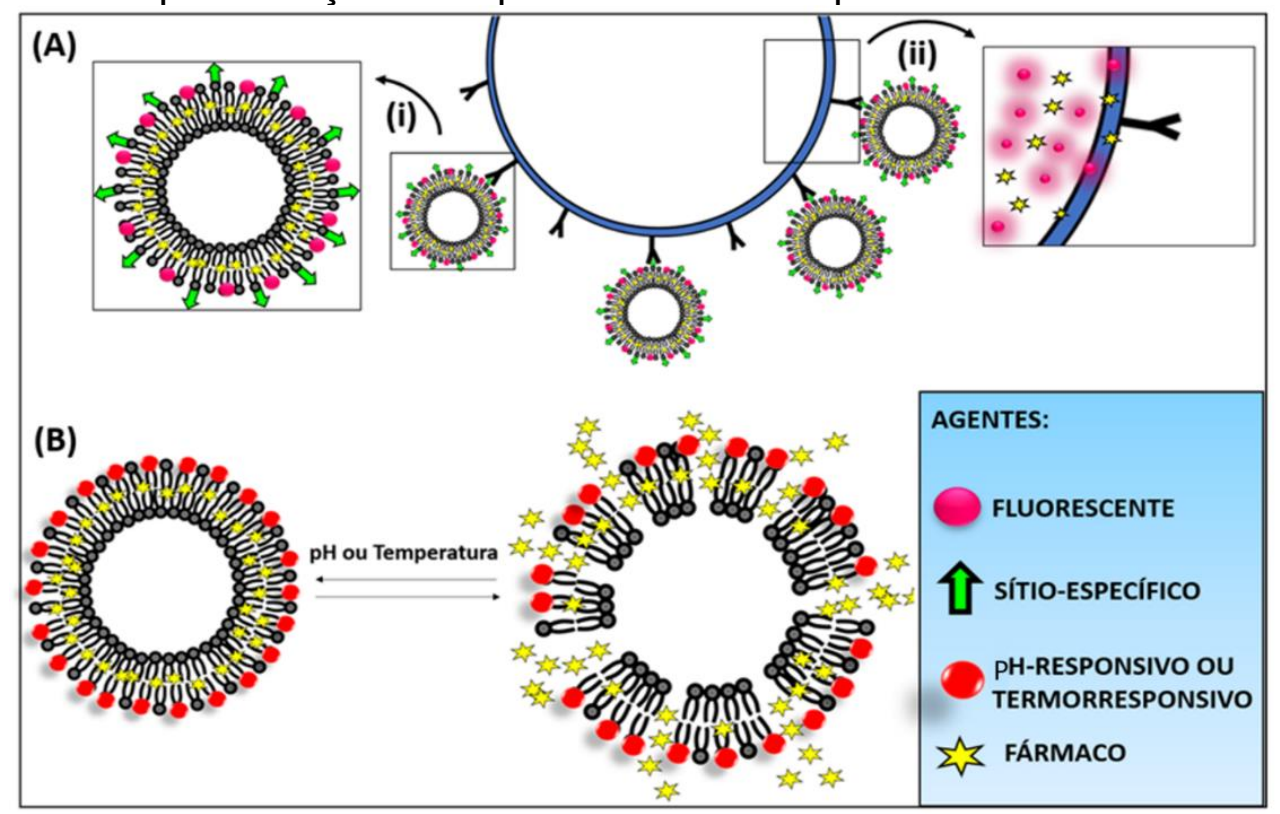

Notas: (A) Lipossomas vetorizados com ligantes específicos e agentes fluorescentes (i) ampliação da estrutura lipossomal teranóstica e (ii) ampliação da estrutura celular após a entrega do fármaco e agentes fluorescentes; (B) Comportamento dos lipossomas responsivos ao $\mathrm{pH}$ e temperatura.

Fonte: os autores.

Dentre os principais ligantes utilizados destacam-se as proteínas, como a transferina, proteína responsável pelo transporte de ferro. A sua utilização é relacionada ao fato de células cancerígenas superexpressarem seus receptores 
(TfR1 ou CD71) dada sua essencialidade ao crescimento celular (SMITH et al., 2011; CLARK; DAVIS, 2015; LURIA-PÉREZ; HELGUERA; RODRÍGUEZ, 2016; RONCATO et al., 2018).

Anticorpos monoclonais constituem uma outra vertente muito promissora, primeiramente porque envolvem medicamentos já aprovados como Herceptin® e Rituxan® que apresentam levada afinidade e potencial terapêutico (ATTIA et al., 2019; YOO et al., 2019). A grande vantagem reside não apenas no direcionamento específico, mas também na transdução de sinais, regulando a expressão de proto-oncogenes possibilitando a alteração dos mecanismos de proliferação celular.

Polissacarídeos também vêm sendo aplicados, como exemplo o ácido hialurônico, um glicosaminoglicano, presente na matriz extracelular que interage especificamente com receptores CD44 do epitélio intestinal (CHOI et al., 2011).

Outros ligantes incluem peptídeos (RGD, IL4RPep-1,NGR) com elevada afinidade e capazes de aumentar a permeabilidade dos fármacos através dos tumores sólidos (HAUBNER et al., 2005; GREGORC et al., 2009; SUGAHARA et al., 2010; CHI et al., 2015). Os aptâmeros (A-1411, GBI-10, a-Pegaptanib) constituem outra classe de compostos empregada, cujas principais vantagens são a biocompatibilidade, baixa imunogenicidade e seletividade controlável ( $\mathrm{JO}$; BAN, 2016; STEIN; CASTANOTTO, 2017; HE et al., 2018). Por fim, moléculas de baixa massa molecular como ácido fólico, biotina, galactose dentre outras vêm sendo amplamente estudadas devido ao baixa custo de produção, e simplicidade de formulação e especificidade das interação ligante/receptor (DESHAYES et al., 2013; LEDERMANN; CANEVARI; THIGPEN, 2015; HUO et al., 2017; LV et al., 2017; PELLOSI et al., 2017; DE FREITAS et al., 2019).

Os lipossomas representados na Figura 5A além de apresentarem os ligantes sítio-específicos, também podem apresentar agentes de diagnóstico em sua superfície, formando lipossomas teranósticas. Estas são nanoplataformas moleculares que simultaneamente permitem o diagnóstico de doenças. Dentre os principais agentes de diagnóstico, nanopartículas metálicas e compostos fluorescentes vêm sendo amplamente utilizados (KELKAR; REINEKE, 2011; HEO et al., 2012; SELECI et al., 2017). Caso possuam agentes ligantes e biomarcadores, podem também promover o tratamento de doenças específicas (SELECl et al., 2017). Dessa forma, é possível que um fármaco seja direcionado a algum receptor tumoral específico, e não a todas as células do organismo.

Lipossomas sensíveis a alterações no $\mathrm{pH}$ e na temperatura também vêm sendo desenvolvidos, conforme Figura 5B. Um lipossoma pH-responsivo é geralmente estável em $\mathrm{pH}$ fisiológico, mas pode ser submetido a desestabilização sob condições ácidas, levando à liberação dos princípios ativos encapsulados (SIMÕES et al., 2004; CHIANG; LO, 2014). Lipossomas pHresponsivos foram idealizados após a consideração de que alguns tecidos patológicos, incluindo tumores ou áreas de inflamação e infecção, exibem um ambiente ácido em comparação com os tecidos normais (RIEMANN et al., 2011). Os primeiros sistemas lipossomais deste tipo foram desenvolvidos no início da década de oitenta visando a entrega seletiva de fármacos para regiões contendo tumores primários ou metastáticos (YATVIN et al., 1980). A principal estratégia na obtenção de lipossomas pH-responsivos está relacionada à combinação de 
fosfatidiletanolamina (PE) com compostos contendo grupos ácidos (PALIWAL; PALIWAL; VYAS, 2015).

Lipossomas termorresponsivos, por sua vez, foram inicialmente obtidos no final da década de setenta (YATVIN et al., 1978). O estudo trouxe uma formulação lipossomal sensível à temperatura, capaz de liberar um fármaco hidrofílico acima da temperatura fisiológica (YATVIN et al., 1978). No início do século XXI, os ensaios clínicos envolvendo lipossomas termorresponsivos passaram a ser conduzidos em humanos (LANDON et al., 2013). De modo geral, são capazes de liberar os fármacos encapsulados em temperaturas superiores à sua temperatura de transição da fase $\left(T_{m}\right)$, ou seja, quando passam da fase ordenada para a fase fluida. Em geral, o processo de liberação ocorre devido a hipertermia observada em regiões tumorais em relação aos tecidos saudáveis (KONING et al., 2010). Nesse caso, há o aumento seletivo da biodisponibilidade do fármaco localmente, minimizando a exposição sistêmica. Geralmente são sistemas lipossomais baseados em dipalmitoilfosfocolina (DPPC) como componente principal. A obtenção de lipossomas termorresponsivos pode ser mediada pela adição de polímeros termossensíveis à formulação (KNEIDL et al., 2014).

A preparação de lipossomas de longa-circulação com base na utilização de copolímeros tribloco tem apresentado resultados promissores na melhoria de transporte e biodisponibilização de fármacos. Inclui-se ainda, a redução nos custos de produção, obtenção, reprodutibilidade, rapidez e estabilidade das formulações. Nos próximos anos, muitos trabalhos serão desenvolvidos visando a funcionalização de sistemas lipossomais que possam permitir a realização de procedimentos e tratamentos mais seguros, rápidos e eficazes. As próximas etapas devem direcionar esse tipo de formulação aos estágios iniciais dos testes clínicos. Em breve, espera-se que diversos medicamentos, principalmente anticancerígenos estabilizados em sistemas de fosfolipídios modificados, possam ser aprovados para aplicações clínicas.

\section{CONCLUSÕES}

A modificação de lipossomas por meio da nanotecnologia é uma alternativa inovadora e promissora para a formulação, biotransporte e entrega seletiva de fármacos. Os entraves associados à baixa estabilidade em solução e baixo tempo de circulação sanguínea, até então característicos dos lipossomas convencionais, vêm impulsionando a comunidade científica no desenvolvimento de sistemas altamente estabilizados e funcionalizados.

Como descrito neste artigo de revisão, uma quantidade significativa de publicações tem demonstrado que as modificações superficiais com materiais hidrofílicos e ligantes específicos tem contribuído amplamente na resolução dos problemas associados ao tratamento de doenças como o câncer. As várias etapas desde a modulação do tipo de cadeia, tamanho das vesículas, utilização de GM1 e PEG contribuíram para o desenvolvimento dos fosfolipídios estabilizados com Poloxâmeros.

Nos próximos anos, almeja-se a obtenção de sistemas de formulação ainda mais sofisticados, biocompatíveis, mais estáveis, com longo tempo de 
circulação sanguínea, baixo custo e, acima de tudo, que possam ser acessíveis à população em geral.

\section{REFERÊNCIAS}

A'HERN, R. P.; GORE, M. E. Impact of doxorubicin on survival in advanced ovarian cancer. Journal of Clinical Oncology, v. 13, n. 3, p. 726-732, 1995.

AKASH M. S. H.; REHMAN K. Recent progress in biomedical applications of pluronic (PF127): Pharmaceutical perspectives. Journal of Controlled Release, v. 209, p. 120-138, 2015.

AKBARZADEH, A. et al. Liposome : classification , preparation and applications. Nanoscale Research Letters, v. 8:102, n. 1, p. 1-9, 2013.

ALEXANDRIDIS, P.; HATTON, T. A. Poly(ethylene oxide)-poly(propylene oxide )-poly (ethylene oxide) block copolymer surfactants in aqueous solutions and at interfaces: thermodynamics, structure, dynamics, and modeling. Colloids and Surfaces A: Physicochemical and Engineering Aspects, v. 96, p. 1-46, 1995.

ALEXANDRIDIS, P.; HOLZWARTHF, J. F.; HATTON, T. A. Micellization of poly(ethylene oxide)-poly(propylene oxide)-poly(ethylene oxide) triblock copolymers in aqueous solutions: thermodynamics of copolymer association. Macromolecules, v. 27, p. 2414-2425, 1994.

ALLEN, T. M. Liposomal Drug Formulations. Drugs, v. 56(5), n. April, p. 747756, 2015.

ALLEN, T. M.; HANSEN, C.; RUTLEDGE, J. Liposomes with prolonged circulation times: factors affecting uptake by reticuloendothelial and other tissues. Biochimica et Biophysica Acta (BBA) - Biomembranes, v. 981, p. 2735, 1989.

ATTIA, M. F. et al. An overview of active and passive targeting strategies to improve the nanocarriers efficiency to tumour sites. Journal of Pharmacy and Pharmacology, v. 71, n. 8, p. 1185-1198, 2019.

AULA, S. et al. Biophysical, biopharmaceutical and toxicological significance of biomedical nanoparticles. RSC Advances, v. 5, n. 59, p. 47830-47859, 2015.

BATISTA, C. M. et al. Lipossomas e suas aplicações terapêuticas: Estado da arte. Brazilian Journal of Pharmaceutical Sciences, v. 43, p. 167-179, 2007.

BELTRÁN-GRACIA, E. et al. Nanomedicine review: Clinical developments in liposomal applications. Cancer Nanotechnology, v. 10, n. 1, p. 1-40, 2019.

BODRATTI, A. M.; ALEXANDRIDIS, P. Formulation of poloxamers for drug delivery. Journal of Functional Biomaterials, v. 9, n. 1, p. 1-24, 2018. 
BRIUGLIA, M. L. et al. Influence of cholesterol on liposome stability and on in vitro drug release. Drug Delivery and Translational Research, v. 5, n. 3, p. 231-242, 2015.

BUGELSKI, P. et al. Analysis of the Fate of Systemically Administered Liposomes and Implications for Their Use in Drug Delivery. Cancer Research, v. 42, n. 4, p. 1412-1422, 1982.

BULBAKE, U. et al. Liposomal formulations in clinical use : an updated review development. Pharmaceutics, v. 9, p. 1-33, 2017.

CHANDAROY, P. et al. Utilizing temperature-sensitive association of Pluronic F127 with lipid bilayers to control liposome-cell adhesion. Biochimica et Biophysica Acta - Biomembranes, v. 1559, n. 1, p. 32-42, 2002.

CHEN, C. et al. An overview of liposome lyophilization and its future potential. Journal of Controlled Release, v. 142, n. 3, p. 299-311, 2010.

CHI, L. et al. Enhanced delivery of liposomes to lung tumor through targeting interleukin-4 receptor on both tumor cells and tumor endothelial cells. Journal of Controlled Release, v. 209, p. 327-336, 2015.

CHIANG, Y.; LO, C. Biomaterials pH-Responsive polymer-liposomes for intracellular drug delivery and tumor extracellular matrix switched-on targeted cancer therapy. Biomaterials, v. 35, n. 20, p. 5414-5424, 2014.

CHOI, K. Y. et al. Smart nanocarrier based on PEGylated hyaluronic acid for cancer therapy. ACS Nano, v. 5, n. 11, p. 8591-8599, 2011.

CLARK, A. J.; DAVIS, M. E. Increased brain uptake of targeted nanoparticles by adding an acid-cleavable linkage between transferrin and the nanoparticle core. Proceedings of the National Academy of Sciences of the United States of America, v. 112, n. 40, p. 12486-12491, 2015.

COUVREUR, P. Nanoparticles in drug delivery: past, present and future. Advanced Drug Delivery Reviews, v. 65, n. 1, p. 21-23, 2013.

CROWE, L. M.; REID, D. S.; CROWE, J. H. Is trehalose special for preserving dry biomaterials? Biophysical Journal, v. 71, p. 2087-2093, 1996.

D'SOUZA, A. A.; SHEGOKAR, R. Polyethylene glycol (PEG): a versatile polymer for pharmaceutical applications. Expert Opinion on Drug Delivery, v. 13, n. 9, p. 1257-1275, 2016.

DAMS, E. L. S. T. M. et al. Accelerated Blood Clearance and Altered Biodistribution of Repeated Injections of Sterically Stabilized Liposomes 1. The journal of pharmacology and experimental therapeutics, v. 292, n. 3, p. 
1071-1079, 2000.

DAVE, V. et al. Lipid-polymer hybrid nanoparticles: Synthesis strategies and biomedical applications. Journal of Microbiological Methods, v. 160, $\mathrm{n}$. January, p. 130-142, 2019.

DE FREITAS, C. F. et al. "Biotin-targeted mixed liposomes: A smart strategy for selective release of a photosensitizer agent in cancer cells". Materials Science and Engineering: C, v. 104, p. 1-12, 2019.

DESHAYES, S. et al. Phenylboronic acid-installed polymeric micelles for targeting sialylated epitopes in solid tumors. Journal of the American Chemical Society, v. 135, n. 41, p. 15501-15507, 2013.

DO AMARAL, A. T. et al. A evolução da Química Medicinal no Brasil: Avanços nos 40 anos da Sociedade Brasileira de Química. Quimica Nova, v. 40, n. 6, p. 694-700, 2017.

EL-KAMEL, A. H. In vitro and in vivo evaluation of Pluronic F127-based ocular delivery system for timolol maleate. International Journal of Pharmaceutics, $v$. 241, p. 47-55, 2002.

FANCIULLINO, R.; CICCOLINI, J. Liposome-Encapsulated Anticancer Drugs: Still Waiting for the Magic Bullet? Current Medicinal Chemistry, v. 16, p. 43614373, 2009.

FANG, J.; NAKAMURA, H.; MAEDA, H. The EPR effect: Unique features of tumor blood vessels for drug delivery, factors involved, and limitations and augmentation of the effect. Advanced Drug Delivery Reviews, v. 63, n. 3, p. 136-151, 2011.

FEITOSA, E.; WINNIK, M. Interaction between Pluronic F127 and Dioctadecyldimethylammonium Bromide ( DODAB ) Vesicles Studied by Differential Scanning Calorimetry. Langmuir, v. 26, n. 22, p. 17852-17857, 2010.

FREITAS, C. F. DE et al. PEG-coated vesicles from Pluronic/lipid mixtures for the carrying of photoactive erythrosine derivatives. Colloids and Surfaces B: Biointerfaces, v. 175, p. 530-544, 2019a.

FREITAS, C. F. DE et al. Rapid Formation of Small Unilamellar Vesicles (SUV) Through Low-Frequency Sonication: an Innovative Approach. Colloids and Surfaces B: Biointerfaces, v. 181, p. 837-844, 2019b.

FRÉZARD, F.; MG, B. H.; ROCHA, O. G. F. Lipossomas: propriedades físicoquímicas e farmacológicas, aplicações na quimioterapia à base de antimônio. Quimica Nova, v. 28, n. 3, p. 511-518, 2005.

FRUHWIRTH, G. O.; LOIDL, A.; HERMETTER, A. Oxidized phospholipids: From 
molecular properties to disease. Biochimica et Biophysica Acta - Molecular Basis of Disease, v. 1772, n. 7, p. 718-736, 2007.

GABIZON, A.; PAPAHADJOPOULOS, D. Liposome formulations with prolonged circulation time in blood and enhanced uptake by tumors. Proceedings of the National Academy of Sciences of the United States of America, v. 85, n. September, p. 6949-6953, 1988.

GREGORC, V. et al. Phase lb study of NGR-hTNF, a selective vascular targeting agent, administered at low doses in combination with doxorubicin to patients with advanced solid tumours. British Journal of Cancer, v. 101, n. 2, p. 219-224, 2009.

GWINN, M. R.; VALLYATHAN, V. Review nanoparticles : health effects - pros and cons. Environmental Health Perspectives, v. 114, n. 12, p. 1818-1825, 2006.

HAKOMORI, S. Glycosphingolipids in cellular interaction, differentiation and oncogenesis. Annual Review of Biochemistry, v. 50, p. 733-764, 1981.

HAUBNER, R. et al. Noninvasive visualization of the activated $\alpha v \beta 3$ integrin in cancer patients by positron emission tomography and [18F]Galacto-RGD. PLoS Medicine, v. 2, n. 3, p. 0244-0252, 2005.

HE, X. et al. Sequentially Triggered Nanoparticles with Tumor Penetration and Intelligent Drug Release for Pancreatic Cancer Therapy. Advanced Science, v. 5, n. 5, p. 1-11, 2018.

HELMS, C. C.; GLADWIN, M. T.; KIM-SHAPIRO, D. B. Erythrocytes and vascular function: Oxygen and nitric oxide. Frontiers in Physiology, v. 9, n. FEB, p. 1-9, 2018.

HEO, D. N. et al. Gold nanoparticles surface-functionalized with paclitaxel drug and biotin receptor as theranostic agents for cancer therapy. Biomaterials, v. 33, n. 3, p. 856-866, 2012.

HUANG, Y.; DAI, W. Fundamental aspects of solid dispersion technology for poorly soluble drugs. Acta Pharmaceutica Sinica B, v. 2013, p. 1-8, 2013.

HUO, M. et al. Tumor-targeted delivery of sunitinib base enhances vaccine therapy for advanced melanoma by remodeling the tumor microenvironment. Journal of Controlled Release, v. 245, p. 81-94, 2017.

HUYNH, N. T.; LAUTRAM, N. The rise and rise of stealth nanocarriers for cancer therapy: passive versus active targeting. Nanomedicine, v. 5, p. 1415-1433, 2010.

IMMORDINO, M. L.; CATTEL, L. Stealth liposomes : review of the basic science, 
rationale, and clinical applications, existing and potential. International Journal of Nano, v. 3, n. April, p. 297-315, 2006b.

ISHIDA, T. et al. Accelerated blood clearance of PEGylated liposomes following preceding liposome injection: Effects of lipid dose and PEG surface-density and chain length of the first-dose liposomes. Journal of Controlled Release, v. 105, n. 3, p. 305-317, 2005.

JO, H.; BAN, C. Aptamer-nanoparticle complexes as powerful diagnostic and therapeutic tools. Experimental and Molecular Medicine, v. 48, n. e230, p. 19, 2016.

JOHNSSON, M. et al. Effect of PEO-PPO PEO triblock copolymers on structure and stability of phosphatidylcholine liposomes. Langmuir, n. 15, p. 6314-6325, 1999.

K.KOSTARELOS; P.F.LUCKHAM; TH.F.TADROS. Addition of block copolymers to liposomes prepared using soybean lecithin. effects on formation, stability and. Journal of Liposome Research, v. 5, n. 1, p. 117-130, 1995.

KELKAR, S. S.; REINEKE, T. M. Theranostics Combining Imaging and Therapy. Bioconjugate Chemistry, v. 22, n. 10, p. 1879-1903, 2011.

KESKINBORA, K. H.; JAMEEL, M. A. Nanotechnology Applications and Approaches in Medicine: A Review. Journal of Nanoscience and Nanotechnology, v. 2, n. 6, p. 1-5, 2018.

KHAN, A. A. et al. Recent strategies towards the surface modification of liposomes: an innovative approach for different clinical applications. 3 Biotech, v. 10, n. 4, p. 1-15, 2020.

KLEMETSRUD, T. et al. Polymer coated liposomes for use in the oral cavity - A study of the in vitro toxicity, effect on cell permeability and interaction with mucin. Journal of Liposome Research, v. 28, p. 1-12, 2016.

KNEIDL, B. et al. Thermosensitive liposomal drug delivery systems : state of the art review. International journal of nanomedicine, v. 16, n. 9, p. 4387-4398, 2014.

KONING, G. A. et al. Hyperthermia and Thermosensitive Liposomes for Improved Delivery of Chemotherapeutic Drugs to Solid Tumors. p. 1750-1754, 2010.

KOSTARELOS, K.; TADROS, T. F.; LUCKHAM, P. F. Physical conjugation of (Tri-) block copolymers to liposomes toward the construction of sterically stabilized vesicle systems. Langmuir, v. 15, n. 2, p. 369-376, 1999.

LANDON, C. D. et al. Nanoscale Drug Delivery and Hyperthermia: The Materials Design and Preclinical and Clinical Testing of Low Temperature- Sensitive 
Liposomes Used in Combination with Mild Hyperthermia in the Treatment of Local Cancer. Open Nanomedicine Journal, v. 1, n. 3, p. 38-64, 2013.

LASIC, D. D.; DAVID NEEDHAM. The "Stealth" liposome: a prototypical biomaterial. Chemical Reviews, v. 95, n. 8, p. 2601-2628, 1995.

LAVERMAN, P. et al. Factors affecting the accelerated blood clearance of polyethylene glycol-liposomes upon repeated injection. Journal of Pharmacology and Experimental Therapeutics, v. 298, n. 2, p. 607-612, 2001.

LE MEINS, J. F. et al. Hybrid polymer/lipid vesicles: State of the art and future perspectives. Materials Today, v. 16, n. 10, p. 397-402, 2013.

LEDERMANN, J. A.; CANEVARI, S.; THIGPEN, T. Targeting the folate receptor: Diagnostic and therapeutic approaches to personalize cancer treatments. Annals of Oncology, v. 26, n. 10, p. 2034-2043, 2015.

LIANG, X.; MAO, G.; NG, K. Y. S. Effect of chain lengths of PEO-PPO-PEO on small unilamellar liposome morphology and stability: An AFM investigation. Journal of Colloid and Interface Science, v. 285, n. 1, p. 360-372, 2005.

LURIA-PÉREZ, R.; HELGUERA, G.; RODRíGUEZ, J. A. Anticuerpos que reconocen el receptor de transferrina en células tumorales. Boletin Medico del Hospital Infantil de Mexico, v. 73, n. 6, p. 372-379, 2016.

LV, Y. et al. Ultrasound-Triggered Destruction of Folate-Functionalized Mesoporous Silica Nanoparticle-Loaded Microbubble for Targeted Tumor Therapy. Advanced Healthcare Materials, v. 6, n. 18, p. 1-10, 2017.

MABREY, S.; STURTEVANT, J. M. Investigation of phase transitions of lipids and lipid mixtures by high sensitivity differential scanning calorimetry. Proc. Natl. Acad. Sci. USA, v. 73, n. 11, p. 3862-3866, 1976.

MEHVAR, R. Clearance concepts: Fundamentals and application to pharmacokinetic behavior of drugs. Journal of Pharmacy and Pharmaceutical Sciences, v. 21S, p. 88s-102s, 2018.

MILLA, P.; DOSIO, F.; CATTEL, L. PEGylation of Proteins and Liposomes: a Powerful and Flexible Strategy to Improve the Drug Delivery. Current Drug Metabolism, v. 13, n. 1, p. 105-119, 2011.

MINEART, K. P. et al. Fabrication and characterization of hybrid stealth liposomes. Macromolecules, v. 51, n. 8, p. 3184-3192, 2018.

MOGHIMI, S. M.; SZEBENI, J. Stealth liposomes and long circulating nanoparticles: critical issues in pharmacokinetics, opsonization and proteinbinding properties. Progress in Lipid Research, v. 42, p. 463-478, 2003. 
MOGHIMIPOUR, E.; HANDALI, S. Liposomes as drug delivery systems: properties and applications. Research Journal of Pharmaceutical, Biological and Chemical Sciences, v. 4, n. March, p. 169-185, 2013.

MUFAMADI, M. S. et al. A Review on Composite Liposomal Technologies for Specialized Drug Delivery. Journal of Drug Delivery, v. 2011, p. 1-12, 2011.

NAGAYASU, A.; UCHIYAMA, K.; KIWADA, H. The size of liposomes: a factor which affects their targeting efficiency to tumors and therapeutic activity of liposomal antitumor drugs. Advanced Drug Delivery Reviews, v. 40, p. 75-87, 1999.

OGRIS, M. et al. PEGylated DNA / transferrin - PEI complexes: reduced interaction with blood components, extended circulation in blood and potential for systemic gene delivery. Gene Therapy, v. 6, n. December 1998, p. 595-605, 1999.

PALIWAL, S. R.; PALIWAL, R.; VYAS, S. P. A review of mechanistic insight and application of $\mathrm{pH}$-sensitive liposomes in drug delivery. Drug Delivery, v. 22, n. 3, p. 231-242, 2015.

PANDYA, T. et al. Liposomal Formulations In Cancer Therapy: Passive Versus Active Targeting. Asian Journal of Pharmaceutical Research and Development, v. 7, n. 2, p. 35-38, 2019.

PELLOSI, D. S. et al. Multifunctional theranostic Pluronic mixed micelles improve targeted photoactivity of Verteporfin in cancer cells. Materials Science and Engineering C, v. 71, p. 1-9, 2017.

PINNADUWAGE, P.; HUANG, L. $\beta$-Galactosidase-induced destabilization of liposome composed of phosphatidylethanolamine and ganglioside GM1. Biochimica et Biophysica Acta (BBA) - Biomembranes, v. 939, n. 2, p. 375382, 1988.

PIPPA, N. et al. Chimeric lipid/block copolymer nanovesicles: Physico-chemical and bio-compatibility evaluation. European Journal of Pharmaceutics and Biopharmaceutics, v. 107, p. 295-309, 2016.

RIEMANN, A. et al. Acidic environment leads to ROS-Induced MAPK signaling in cancer cells. PLOS ONE, v. 6, n. e22445, p. 1-12, 2011.

RONCATO, F. et al. Improvement and extension of anti-EGFR targeting in breast cancer therapy by integration with the Avidin-Nucleic-Acid-Nano-Assemblies. Nature Communications, v. 9, n. 1, p. 1-11, 2018.

ROOIJEN, N. VAN; SANDERS, A. Kupffer cell depletion by liposome-delivered drugs: comparative activity of intracellular clodronate, propamidine, and 
ethylenediaminetetraacetic acid. Hepatology, v. 23:5, p. 1239-1243, 1996.

SANDEZ-MACHO, I. et al. Interaction of poloxamine block copolymers with lipid membranes: Role of copolymer structure and membrane cholesterol content. Colloids and Surfaces B: Biointerfaces, v. 133, p. 270-277, 2015.

SCHULZ, M.; OLUBUMMO, A.; BINDER, W. H. Beyond the lipid-bilayer: interaction of polymers and nanoparticles with membranes. Soft Matter, v. 8, p. 4849-4864, 2012.

SELECI, M. et al. Theranostic Liposome - Nanoparticle Hybrids for Drug Delivery and Bioimaging. International Journal of Molecular Sciences Article, v. 18, p. $1-11,2017$.

SERCOMBE, L. et al. Advances and Challenges of Liposome Assisted Drug Delivery. Frontiers in Pharmacology, v. 6, n. December, p. 1-13, 2015.

SILVA, J. O. et al. pH-Sensitive, Long-Circulating Liposomes as an Alternative Tool to Deliver Doxorubicin into Tumors: a Feasibility Animal Study. Molecular Imaging and Biology, v. 18, n. May, p. 898-904, 2016.

SIMÕES, S. et al. On the formulation of pH-sensitive liposomes with long circulation times. Advanced Drug Delivery Reviews, v. 56, p. 947-965, 2004.

SINGH, R.; JR, J. W. L. Nanoparticle-based targeted drug delivery. Experimental and Molecular Pathology, v. 86, n. 3, p. 215-223, 2009.

SMITH, B. et al. Hyperthermia-triggered intracellular delivery of anticancer agent to HER2+ cells by HER2-specific affibody (ZHER2-GS-Cys)-conjugated thermosensitive liposomes (HER2+ affisomes). Journal of Controlled Release, v. 153, n. 2, p. 187-194, 2011.

STEIN, C. A.; CASTANOTTO, D. FDA-Approved Oligonucleotide Therapies in 2017. Molecular Therapy, v. 25, n. 5, p. 1069-1075, 2017.

SUGAHARA, K. N. et al. Coadministration of a tumor-penetrating peptide enhances the efficacy of cancer drugs. Science, v. 328, n. 5981, p. 1031-1035, 2010.

TORCHILIN, V. P. et al. Amphiphilic vinyl polymers effectively prolong liposome circulation time in vivo. Biochimica et Biophysica Acta, v. 1195, p. 181-184, 1994.

TORCHILIN, V. P. Recent advances with liposomes as pharmaceutical carriers. Nature Reviews, v. 4, n. February, p. 145-160, 2005.

TRAN, S. et al. Cancer nanomedicine: a review of recent success in drug delivery. Clinical and Translational Medicine, v. 6, n. 44, p. 1-21, 2017. 
TURECEK, P. L. et al. PEGylation of Biopharmaceuticals: A Review of Chemistry and Nonclinical Safety Information of Approved Drugs. Journal of Pharmaceutical Sciences, v. 105, n. 2, p. 460-475, 2016.

WOODLE, M. C. Sterically stabilized liposome therapeutics. Advanced Drug Delivery Reviews, v. 16, n. 2-3, p. 249-265, 1995.

WU, G.; LEE, K. Y. C. Interaction of Poloxamers with Liposomes: An Isothermal Titration Calorimetry Study. Joural of Physical Chemistry B, v. 338, p. 1552215531, 2009.

XING, H.; HWANG, K.; LU, Y. Recent developments of liposomes as nanocarriers for theranostic applications. Theranostics, v. 6, n. 9, p. 1336-1352, 2016.

XU, H. et al. Development of High-Content Gemcitabine PEGylated Liposomes and Their Cytotoxicity on Drug-Resistant Pancreatic Tumour Cells. Pharmaceutical Research, v. 31, n. 10, p. 2583-2592, 2014.

YATVIN, M. B. et al. Design of liposomes for enhanced local release of drugs by hyperthermia. Science, v. 202, n. 4374, p. 1290-1293, 1978.

YATVIN, M. B. et al. Induced drug release from lipid vesicles in serum by $\mathrm{pH}-$ change. Biophysics of Structure and Mechanism, v. 6, n. 3, p. 233-234, 1980.

YOO, J. et al. Active targeting strategies using biological ligands for nanoparticle drug delivery systems. Cancers, v. 11, n. 640, p. 1-13, 2019. 